\title{
Choosing oatmeal porridge and simmered mackerel improves life expectancy in PLOS Medicine: A modeling study.
}

\author{
Content type: Matters Arising \\ Authors: Adam Drewnowski, Jonathan Lara-Arevalo*, Alfonso Mendoza-Velazquez \\ Center for Public Health Nutrition, University of Washington, Seattle, USA \\ *Corresponding author: Jonathan Lara-Arevalo
}

\begin{abstract}
A recent paper in PLOS Medicine showed modeled gains in life expectancy following dietary shifts from a typical Western (TA) to a Feasible (FA) and an Optimal Diet (OD). A Food4HealthyLife calculator was provided on line. However, energy density data for 14 "representative" foods does not correspond to energy density data for 1151 foods in the same food groups from the USDA Department of Agriculture databases. The present recalculation shows that the FA and OD diet plans were lower in saturated fat and added sugar but were higher in energy and sodium, and entailed substantially higher daily diet cost, as based on 2021 national food prices used in the USDA Thrifty Food Plan. First, a diet plan of oatmeal porridge with water, simmered mackerel, half a boiled egg, milk $1 \%$, fresh orange, mixed vegetables, chickpeas, and a handful of nuts and berries is not necessarily the same as a diet of whole grains, seafood, eggs and dairy, vegetables, fruits, nuts and legumes. Second, any well-meaning dietary advice needs to be accompanied by economic feasibility studies and estimates of diet cost. Clinicians, policymakers, and consumers need to understand not only the health impact but also the economic cost of dietary choices. Access to affordable nutrient rich foods is one of the social and political determinants of health.
\end{abstract}

Dietary choices can have an impact on health outcomes (1). A recent modeling study published in PLOS Medicine (2) showed how modeled life expectancy increased when the typical western (TW) dietary pattern was replaced by a healthier and roughly equicaloric feasible diet (FA) and an optimal diet (OD). Examples of representative foods in each food group were provided in Supplemental data (S3) along with their "typical" energy values. The category examples were simmered mackerel, oatmeal porridge with water, mixed vegetables and potatoes; raw orange; peanuts; chickpeas; boiled egg; milk 1\% fat; bread; cutlet; bacon; chicken leg; lemonade; and rapeseed oil. The PLOS Medicine study made a reference to an online Food4HealthyLife calculator that linked gram amounts of the same food groups with desirable health outcomes. 
The PLOS Medicine study (2) then made the claim that increasing the consumption of whole grains, fish, legumes, vegetables, fruits, and nuts contributed to longer life when coupled with reduced consumption of red and processed meat, poultry, eggs and dairy, sugar sweetened beverages, and refined grains (2). However, that claim and the dietary advice seem to have been based on 14 foods only.

The PLOS Medicine study (2) was based in part on consumption data for different food groups from the US Department of Agriculture (3-5). Gains in life expectancy for American men and women, along with other nationalities, were calculated for different age groups. The TW diet featured in PLOS Medicine was very similar to the current US eating patterns.

The present study re-calculated daily energy and calculated both nutrient density and cost of the three food plans (TW, FA, and OD) that were featured in PLOS Medicine. Data on energy density, nutrient composition and food prices for 1,151 foods came from the Food and Nutrition Database for Dietary Studies (FNDDS 2015-16) (6) and from Supplemental Data to the Thrifty Food Plan (TFP) (7). The FNDDS and TFP modeling categories assigned foods into food groups that corresponded to those in PLOS Medicine. The food groups selected were vegetables (including starchy vegetables), whole fruit (but not 100\% juice), whole and refined grains from the grain group, milk and yogurt (but not cheese), processed meat, red meat and while meat (poultry), eggs, fish (but not shellfish), nuts (but not seeds), plant oils (but not margarine or salad dressings), and sugar sweetened beverages (excluding diet). Grains were selected from the USDA grains group only, thus excluding snacks and sweets, sweet bakery goods and other desserts. The assignment of foods into the whole grain category was based on regulations issued by the Food and Drug Administration (FDA). The FDA allows a product to be called whole grain if it contains more than $50 \%$ of whole grain by dry weight (8). The whole grain category included cooked cereals (oatmeal with water), cooked grains (brown rice) as well as whole grain RTE cereals, whole grain pasta and whole grain breads and rolls. All mixed dishes, sauces and condiments, candy, sugars, pizza, and popcorn were excluded.

Energy and retail prices by food group are summarized in Table 1. Shown are USDA TFP modeling categories and food groups listed in PLOS Medicine, as well as means, standard errors, and medians for both energy density and price. The PLOS Medicine study used typical energy density values to establish that the three diet plans (TW, FA, and OD) were equicaloric. Table 1 shows that the typical energy density was not typical at all. With two exceptions (plant oils, beverages), mean energy density of PLOS Medicine typical foods was >=3 SEM above or below the USDA group means for the same food groups. 
Table 1. Energy density (kcal/100g) and price $(\$ / 100 \mathrm{~g})$ by food category based on US Department of Agriculture and FNDDS and Thrifty Food Plan databases.

\begin{tabular}{|c|c|c|c|c|c|c|c|c|c|c|c|}
\hline \multirow{2}{*}{$\begin{array}{l}\text { TFP market } \\
\text { basket categories }\end{array}$} & \multirow[t]{2}{*}{ PLOS groups } & \multicolumn{2}{|c|}{$\begin{array}{l}\text { PLOS ED } \\
\mathrm{kj} / 100 \mathrm{gl}\end{array}$} & \multicolumn{5}{|c|}{$\begin{array}{l}\text { USDA FNDDS } \\
\text { ED kj/100g }\end{array}$} & \multicolumn{3}{|c|}{ USDA TFP prices $\$ / 100 \mathrm{~g}$} \\
\hline & & $\mathrm{N}=$ & $\mathrm{kj} / 100 \mathrm{~g}$ & $\mathrm{~N}=$ & Mean & SEM & Median & $\mathrm{N}=$ & mean & SEM & median \\
\hline Vegetables & Vegetables & 1 & 200 & 180 & 295 & 17.7 & 209 & 180 & 0.76 & 0.07 & 0.47 \\
\hline Whole fruit & Fruit & 1 & 150 & 76 & 411 & 45.7 & 239 & 76 & 0.82 & 0.07 & 0.64 \\
\hline Whole grains & Whole grains & 1 & 400 & 121 & 1207 & 41.4 & 1365 & 121 & 0.68 & 0.03 & 0.71 \\
\hline Refined grains & Refined grains & 1 & 1100 & 198 & 1196 & 27.2 & 1233 & 198 & 0.67 & 0.03 & 0.68 \\
\hline Milk, yogurt & Milk, yogurt & 1 & 170 & 85 & 334 & 17.3 & 306 & 85 & 0.37 & 0.03 & 0.26 \\
\hline Cured meat & Processed meat & 1 & 1900 & 70 & 1155 & 58.7 & 1174 & 70 & 1.68 & 0.13 & 1.21 \\
\hline Red meat & Red meat & 1 & 700 & 63 & 973 & 40.8 & 883 & 63 & 1.74 & 0.08 & 1.57 \\
\hline Poultry & White meat & 1 & 1000 & 123 & 908 & 18.5 & 862 & 123 & 1.09 & 0.04 & 0.93 \\
\hline Eggs & Eggs & 1 & 600 & 55 & 723 & 29.1 & 737 & 55 & 0.51 & 0.04 & 0.39 \\
\hline Seafood & Fish & 1 & 600 & 41 & 791 & 33.9 & 854 & 41 & 2.1 & 0.39 & 1.46 \\
\hline Nuts, seeds, soy & Nuts & 1 & 2600 & 52 & 2413 & 51.6 & 2458 & 52 & 1.8 & 0.13 & 1.84 \\
\hline Oils and fats & Plant oils & 1 & 3700 & 5 & 3673 & 48.0 & 3701 & 5 & 1.13 & 0.40 & 1.06 \\
\hline Beverages & SSB & 1 & 200 & 60 & 195 & 20.0 & 176 & 60 & 0.2 & 0.02 & 0.14 \\
\hline & & 14 & & 1151 & & & & 1151 & & & \\
\hline
\end{tabular}


In the PLOS Medicine article, energy content of the diet declined on going from TW to the OD diet (8085 $\mathrm{kj}$ to $7615 \mathrm{kj}$ ) Based on mean energy content of 1151 foods in the same food groups, daily energy intakes increased very substantially from $2350 \mathrm{kcal} / \mathrm{d}$ (TW) to $2577 \mathrm{kcal} / \mathrm{d}$ (FA) and then to $2804 \mathrm{kcal} / \mathrm{d}$ (OD). Based on median energy content by food group, dietary energy intakes increased from $9167 \mathrm{kj}$ (TW) to $11088 \mathrm{kj}(\mathrm{OD})$. These data are shown in Table 2.

Much of the increase in dietary energy was due to whole grain breads and rolls, important sources of whole grains in the US diet. Restricting the whole grains category to oatmeal porridge and cooked rice (energy density $400 \mathrm{kj} / 100 \mathrm{~g}$ ) still led to an increase in dietary energy from 9,436 kj/d (TW) to 9,928 kj/d (OD). Based on the gram amounts of foods from different food groups, the OD diet plan was lower in added sugar and saturated fat but was higher in sodium.

The present data on national food prices in the US came from the August 2021 revision of the Thrifty Food Plan (TFP) (7). The TFP is a linear programming model used to create an optimized diet that meets multiple nutrition, social, and cost constraints. Among the TFP modeling categories were vegetables, fruit, beans and legumes, nuts, fish, eggs, milk and dairy, red and processed meat, poultry, sweetened beverages, and whole and refined grains.

Table 2 shows that the FA and OD diet plans were associated with higher daily diet costs compared to the TW plan. Daily costs were estimated based on the sum of mean or median prices per food group and specified gram amounts (2). This increase was observed for mean costs (12.03 USD to 15.50 USD) and median costs for each food group (9.40 USD to 11.76 USD). These increases held even when oatmeal porridge with water was the only type of whole grain allowed.

Taking mean prices for foods above and below the median from each food group allowed us to calculate the cost of more affordable and less affordable versions of the TW, FA and OD diet plans. The lower cost version of the OD was estimated at $8.34 \mathrm{USD} / \mathrm{d}$, whereas the higher cost version was estimated at 22.47 $\mathrm{USD} / \mathrm{d}$.

Table 2. Energy and nutrient values and total estimated cost for the TW, FA and OD diets.

\begin{tabular}{|l|r|r|r|}
\hline & $\begin{array}{l}\text { Typical Western } \\
\text { Diet }\end{array}$ & $\begin{array}{l}\text { Feasibility } \\
\text { Approach }\end{array}$ & \multicolumn{1}{l|}{ Optimized Diet } \\
\hline Fadnes et al (2) & $\mathbf{8 , 0 8 5} \mathbf{~ k J ~ ( 1 , 9 3 1 ~ k c a l )}$ & $\mathbf{7 , 8 5 0}$ kJ (1,875 kcal) & 7,615 kJ (1,819 kcal) \\
\hline Total Kj (kcals) from means & $9,839(2,350)$ & $10,791(2,577)$ & $11,743(2,805)$ \\
\hline Total Kj (kcal) from medians & $9,167(2,189)$ & $10,128(2,419)$ & $11,089(2,648)$ \\
\hline & & & 13.77 \\
\hline Total cost (mean) USD/day. & 12.03 & 10.58 & 11.76 \\
\hline Total cost (median) USD/day & 9.40 & & 8.34 \\
\hline
\end{tabular}




\begin{tabular}{|l|r|r|r|}
\hline High cost version (mean) USD/day & 17.23 & 19.85 & 22.47 \\
\hline & & & 18.42 \\
\hline Saturated fat (medians) & 20.48 & 110.34 & 10.37 \\
\hline Total sugar (medians) & 120.1 & $3,401.25$ & $3,744.75$ \\
\hline Sodium (medians) & $3,057.75$ & & \\
\hline
\end{tabular}

Modeling optimized diets with respect to health outcomes depends on multiple assumption and those ought to be driven by the data. When offering model based dietary advice, it is important to be clear on two points. The first is not to base global recommendations on an overly narrow database. A diet plan of oatmeal porridge with water, simmered mackerel, half a boiled egg, and a handful of nuts and berries can be very different from a varied diet of whole grains, seafood, eggs and dairy, fruits, nuts and legumes. Restricting the whole grain category oatmeal porridge and cooked brown rice does not acknowledge the wide range of whole grain foods in the food supply. Broad generalizations to global eating patterns may be out of place when based on very limited nutrient composition data.

Second, model-based dietary advice needs to be economically feasible. Yes, the consumption of vegetables, fruits, legumes, nuts, fish and whole grains has been associated - repeatedly - with positive health outcomes $(9,10)$. It has not escaped anyone's attention that these foods tend to cost more than refined grains, snacks and sweets, and sugar-sweetened beverages (11). For comparison purposes, the modeled cost of the recently updated Thrifty Food Plan is 8.80USD/d for men aged 19-50 and 7.72USD/d for women aged 1950y. The USDA calculates the cost of the Moderate Food Plan at 11.00 USD/d and the Liberal Food Plan at 13.50 USD/d. The estimated cost of the OD diet plan (2) ranged from 8.34USD/d (low-cost version) to 22.47USD/d (higher cost version). The lower calculated cost is very close to the modeled TFP that was based on the same 2021 food prices. On the other hand, the higher-cost OD version would cost 8,201 USD/year or potentially over 32,000 USD/y for a family of four. Past studies based on observed dietary patterns (12) found that the cost differential between healthy and less healthy diets in the US was only about 1.50 USD/day. Whether extra 1.50 US per day is little or a lot depends on one's position along the socioeconomic scale.

Following the approach taken by the USDA Thrifty Food Plan, the healthfulness of diets needs to be assessed against their economic cost. To give one example, the modeled EAT Lancet diet was not affordable by the global poor $(13,14)$. A recent FAO report (15) estimated healthy diets to be up to five times more expensive than diets that met energy requirements through a starchy staple. Other studies pointed to a price differential between energy adequate diets, nutrient adequate diets and optimal healthy diets $(16,17)$. Based on such studies, the USDA acknowledged that former levels of food assistance were inadequate to support healthy diets and increased Supplemental Nutrition Assistance Program (SNAP) 
benefits by $21.03 \%$ effective October 1, 2021. Mandated by the Farm Bill, that was the first revision of the TFP in 45 years.

When modeling the likely impact of an optimized diet on health, it is important to select a broad range of affordable foods. Modifying intakes of fruits, vegetables, whole grains, refined grains, nuts, legumes, meats, fish, eggs, and milk/dairy may well increase life expectancy. However, broad generalizations to potential health outcomes ought to acknowledge food prices and nutrient density of foods.

\section{Conflicts of Interest:}

$\mathrm{AD}$ is the original developer of the Naturally Nutrient Rich and the Nutrient Rich Food (NRF) indices. That work was supported at the time by the Nutrient Rich Coalition whose members were The Beef Checkoff Program through the National Cattlemen's Beef Association, California Avocado Commission, California Kiwifruit, California Strawberry Commission, Egg Nutrition Center, Florida Department of Citrus, Grain Foods Foundation, National Dairy Council, National Pork Board, United States Potato Board, Wheat Foods Council, and Wild Blueberry Association of North America. AD has received grants, contracts, and honoraria from entities both public and private with an interest in nutrient density metrics and nutrient profiling of foods. JLA and AMV have no conflict of interest. 


\section{References}

1. Harmon BE, Boushey CJ, Shvetsov YB, Ettienne R, Reedy J, Wilkens LR, et al. Associations of key diet-quality indexes with mortality in the Multiethnic Cohort: the Dietary Patterns Methods Project. Am J Clin Nutr. 2015 Mar;101(3):587-97.

2. Fadnes LT, Økland J-M, Haaland ØA, Johansson KA. Estimating impact of food choices on life expectancy: A modeling study. PLOS Med. 2022 Feb 8;19(2):e1003889.

3. USDA ERS - Food Consumption and Nutrient Intakes [Internet]. [cited 2022 Feb 16]. Available from: https://www.ers.usda.gov/data-products/food-consumption-and-nutrient-intakes/food-consumptionand-nutrient-intakes/\#Food\%20Consumption\%20Estimates

4. Lin B-H, Yen ST. The U.S. Grain Consumption Landscape: Who Eats Grain, in What Form, Where, and How Much?:35.

5. 2015-2020 Dietary Guidelines | health.gov [Internet]. [cited 2022 Feb 16]. Available from: https://health.gov/our-work/nutrition-physical-activity/dietary-guidelines/previous-dietaryguidelines/2015

6. U.S. Department of Agriculture, Agricultural Research Service. 2018. USDA Food and Nutrient Database for Dietary Studies 2015-2016. Food Surveys Research Group Home Page, http://www.ars.usda.gov/nea/bhnrc/fsrg.

7. U.S. Department of Agriculture. Thrifty Food Plan, 2021 [Internet]. U.S. Department of Agriculture, Food and Nutrition Service, Center for Nutrition Policy and Promotion; 2021 Aug [cited 2022 Feb 16]. Available from: https://www.fns.usda.gov/cnpp/usda-food-plans-cost-food-reports

8. FDA C for FS and A. Health Claim Notification for Whole Grain Foods. FDA [Internet]. 2020 Feb 5 [cited 2022 Feb 16]; Available from: https://www.fda.gov/food/food-labeling-nutrition/health-claimnotification-whole-grain-foods

9. Aune D, Giovannucci E, Boffetta P, Fadnes LT, Keum N, Norat T, et al. Fruit and vegetable intake and the risk of cardiovascular disease, total cancer and all-cause mortality-a systematic review and doseresponse meta-analysis of prospective studies. Int J Epidemiol. 2017 Jun 1;46(3):1029-56.

10. Dinu M, Pagliai G, Sofi F. A Heart-Healthy Diet: Recent Insights and Practical Recommendations. Curr Cardiol Rep. 2017 Aug 24;19(10):95.

11. Drewnowski A, Darmon N. The economics of obesity: dietary energy density and energy cost. Am J Clin Nutr. 2005 Jul;82(1 Suppl):265S-273S.

12. Rao M, Afshin A, Singh G, Mozaffarian D. Do healthier foods and diet patterns cost more than less healthy options? A systematic review and meta-analysis. BMJ Open. 2013 Dec 1;3(12):e004277.

13. Hirvonen K, Bai Y, Headey D, Masters WA. Affordability of the EAT-Lancet reference diet: a global analysis. Lancet Glob Health. 2020 Jan;8(1):e59-66.

14. Willett W, Rockström J, Loken B, Springmann M, Lang T, Vermeulen S, et al. Food in the Anthropocene: the EAT-Lancet Commission on healthy diets from sustainable food systems. The Lancet. 2019 Feb 2;393(10170):447-92. 
15. FAO I. The State of Food Security and Nutrition in the World 2020: Transforming food systems for affordable healthy diets [Internet]. Rome, Italy: FAO, IFAD, UNICEF, WFP and WHO; 2020 [cited 2022 Feb 16]. 320 p. (The State of Food Security and Nutrition in the World (SOFI)). Available from: https://www.fao.org/documents/card/en/c/ca9692en/

16. Bai Y, Herforth A, Masters WA. Global variation in the cost of a nutrient-adequate diet by population group: an observational study. Lancet Planet Health. 2022 Jan;6(1):e19-28.

17. Bai Y, Alemu R, Block SA, Headey D, Masters WA. Cost and affordability of nutritious diets at retail prices: Evidence from 177 countries. Food Policy. 2021 Feb 1;99:101983. 